\title{
Synthesis of Hybrid Monolithic Columns Using a Click Chemistry Reaction for Application in Capillary Liquid Chromatography
}

\author{
Marcella E. P. Schmidt ${ }^{a}$ and Carla B. G. Bottoli ${ }^{\circledR *, a}$ \\ ${ }^{a}$ Instituto de Química, Universidade Estadual de Campinas, \\ PO Box 6154, 13084-971 Campinas-SP, Brazil
}

\begin{abstract}
Hybrid monolithic columns present characteristics of both silica and organic monoliths, such as good mechanical properties, wide $\mathrm{pH}$ tolerance, high permeability and stability and little swelling or shrinkage. A common way to prepare this type of material is by using alkoxysilanes and organic monomers via the sol-gel process and click chemistry reactions. In this paper, a co-condensation organic-silica hybrid monolith was prepared based on tetramethoxysilane (TMOS) and vinyltrimethoxysilane (VTMS) as precursors for the sol-gel process. The hybrid monolithic matrix was modified with dodecanethiol through the thiol-ene click chemistry reaction and the resulting material was compared with a dodecanesilane bonded phase column, in order to evaluate the differences in the chromatographic performance of a stationary phase prepared by a classic reaction or by a thiol-ene click reaction. Additionally, the stability of the thiol-ene column over time was evaluated. The effects of different synthetic proportions were investigated in detail by scanning electron microscopy (SEM), scanning capacitively coupled contactless conductivity detection $\left(\mathrm{sC}^{4} \mathrm{D}\right)$, Fourier-transform infrared spectroscopy (FTIR) and retention behavior in capillary liquid chromatography (cLC). The hybrid monolithic column prepared with dodecanethiol was the best one for the separation of alkylbenzenes and polycyclic aromatic hydrocarbons by cLC-UV.
\end{abstract}

Keywords: hybrid monolith column, capillary liquid chromatography, thiol-ene click chemistry reactions, sol-gel process

\section{Introduction}

Capillary liquid chromatography (cLC) is based on the same concepts as high-performance liquid chromatography (HPLC), but the inner diameters of the columns $(0.1-0.5 \mathrm{~mm})$ are reduced, requiring resizing of the tubings, pumps, injectors and detectors. This reduction results in lower consumption of mobile phase, better column performance and easier interfacing with other techniques, especially mass spectrometry (MS)., ${ }^{1,2}$ Evolving from HPLC to CLC, there are also advances in the materials used as stationary phases for capillary columns in cLC. The newest stationary phases for capillary columns are more efficient, allow higher flow rates with a minimum of increased pressure, have higher plate numbers and higher permeability, due to less mass transfer, lower pressures and higher porosities. ${ }^{3-8}$ There are three types of columns that can be used in CLC: packed columns, open-tubular columns and monolithic columns. Since the beginning of cLC, monolithic columns have

*e-mail: carlab@unicamp.br aroused interest in separation science mainly because of their advantages, compared to packed columns..$^{910}$

According to Guiochon, ${ }^{11}$ a monolith is a continuous block of a porous and permeable material, in which solvent can percolate and has a large enough surface area to exhibit retention of a significant number of analytes. The morphological characteristics of monolithic columns and wide functionalization diversity for specific applications are advantages that indicate that monoliths are an alternative to packed columns.

The monolithic stationary phases can be classified in three categories; inorganic silica-based, ${ }^{3,9}$ polymer-based ${ }^{12}$ and organic-silica hybrid based. ${ }^{13}$ Since 2000 , the latter has been attracting much research as an alternative that combines the best characteristics of inorganic and organic columns.

In 2000, Hayes and Malik ${ }^{13}$ synthesized the first organic-silica hybrid monolithic column, initiating a new manner to synthesize the monoliths, based on the direct incorporation of organic portions in the silica matrix via the sol-gel process. ${ }^{14}$ Such syntheses generate materials with advantages compared to other types of monoliths, 
such as good mechanical properties, less shrinkage during the manufacturing process, wide tolerance to $\mathrm{pH}$, high permeability and good column efficiency. ${ }^{14-18}$

The preparation of hybrid monoliths can be carried out by different processes: (a) sol-gel synthesis using tri- and tetra-alkoxysilanes with organic groups as precursors; (b) reactions with organic-inorganic (non-silica) reagents; (c) reactions with organic-silica/metal reagents; (d) free radical polymerization; (e) ring-opening polymerization and (f) one-pot chemistry using: (i) alkoxysilanes with organic monomers and (ii) polyhedral oligomeric silsesquioxanes-based monomers (POSS). This last one can occur in two different solution systems: organic solvent/ aqueous solution and nonaqueous solution. ${ }^{3,10,12,14,19}$ There are other approaches to the preparation of hybrid monolithic columns that use ionic liquids and nanoparticles of carbon, gold or silica. ${ }^{8}$ In the processes of sol-gel synthesis, groups can be incorporated after synthesis by secondary reactions to achieve specific characteristics. One way to do this is via click chemistry reactions, which result in improved efficiency and selectivity of the materials. ${ }^{20}$ The use of click chemistry reactions allows a high conversion under mild conditions, being simple and efficient syntheses. These properties bring a considerable improvement to the synthesis of new stationary phase materials, especially in microsystems, such as monolithic columns. Thus, using these reactions to synthesize capillary monolithic columns could present benefits making click chemistry reactions an interesting way of synthesis to be explored for capillary and nano-LC.

This type of chemical reaction was defined by Sharpless and co-workers ${ }^{21}$ in 2001 as "a set of powerful, highly reliable and selective reactions for rapid synthesis of new compounds via heteroatom $(\mathrm{C}-\mathrm{X}-\mathrm{C})$ bonds". In the context of separation chemistry, more specifically for the production of monolithic columns, the click-polymerizations reactions can be classified as: (i) azide-alkyne cycloaddition catalyzed by copper(I) (CuAAC); (ii) ring-opening polymerization; (iii) thiol-ene/ ino and (iv) thiol-(meth) acrylate. ${ }^{8,20}$ Specifically, for the preparation of monolithic columns, these reactions must be non-reactive towards oxygen and occur only within the capillary. Among the types of click chemistry reactions, thiol-ene is the most commonly used today for obtaining monolithic materials..$^{2,16,20,22-25}$ Zou and co-workers ${ }^{16}$ prepared hybrid monoliths via sol-gel chemistry and the surface was tailored via a thiol-ene click reaction by using 1-octadecanethiol, sodium 3-mercapto-1-propanesulfonate and 2,2-(ethylenedioxy)diethanethiol/vinylphosphonic acid. Also, the preparation of octadecyl-functionalized and strong cation exchange (SCX) monolithic columns has been investigated for proteomic analysis in CLC-MS/MS and in SCX-reversed phase (RP)LC-MS/MS, respectively. ${ }^{16}$

In this work, we present the preparation of an organicsilica hybrid monolith, prepared using tetramethoxysilane (TMOS) and vinyltrimethoxysilane (VTMS) as precursors for the sol-gel process. Through the thiol-ene click reaction, a new stationary phase was prepared using dodecanethiol to modify the hybrid monolithic matrix in order to increase hydrophobic interactions inside the column. A hypervinylization reaction was also evaluated before the thiol-ene reaction to ensure that all the sites on the monolith surface were replaced by vinyl groups and were suitable for the thiol-ene reaction. We have examined the effects of functional organic moieties comparing dodecanethiol with a dodecanesilane bonded phase tailored on a surface of a hybrid monolith. The stability of the thiol-ene column was evaluated as well as the morphology of the columns using scanning electron microscopy (SEM), scanning capacitively coupled contactless conductivity detection $\left(\mathrm{sC}^{4} \mathrm{D}\right)$, Fouriertransform infrared spectroscopy (FTIR) and the retention behavior of test compounds in cLC.

\section{Experimental}

\section{Chemicals and materials}

All the reagents were of analytical grade. Tetramethoxysilane (TMOS), vinyltrimethoxysilane (VTMS), poly(ethylene glycol) (PEG, $\mathrm{Mn}=10000 \mathrm{~g} \mathrm{~mol}^{-1}$ ), glacial acetic acid, triethylamine (TEA), dodecanethiol (DDT), 2,2'-azobisisobutyronitrile (AIBN), trichlorododecylsilane (TCDDS) and the standards of alkylbenzenes were obtained from Sigma-Aldrich (Steinheim, Germany). The sodium hydroxide solution was obtained from Agilent Technologies (Walbronn, Germany), vinyldimethylethoxysilane (VDMES) was obtained from BeanTown Chemical Inc. (Hudson, MA, USA) and urea was obtained from Riedel-de Haën (Seelze, Germany). Methanol, diethyl ether and acetonitrile, all HPLC grade, were obtained from Tedia (Fairfield, USA). Fused-silica capillaries with $100 \mu \mathrm{m}$ ID and $360 \mu \mathrm{m}$ OD were purchased from Agilent Technologies (Waldbronn, Germany) and the water used in the experiments was purified by a Milli-Q system from Millipore (Bedford, USA).

\section{Pretreatment of the capillary}

Prior to use, the fused-silica capillary was washed and filled with $1.0 \mathrm{~mol} \mathrm{~L}^{-1}$ sodium hydroxide solution, using a KDS-100 syringe pump, KdScientific (Holliston, USA), 
sealed with rubber connectors and kept in a vacuum oven model LSDZF-6021 from Logen Scientific (Diadema, Brazil) at $120^{\circ} \mathrm{C}$ for $2 \mathrm{~h}$. Next, the capillary was flushed with purified water to neutrality and dried by purging with nitrogen gas for $1 \mathrm{~h}$.

\section{Preparation of the monolithic columns}

The pre-polymerization mixture was prepared based on that of Liu et al., ${ }^{16}$ in which hybrid silica monoliths were first synthesized by a sol-gel synthesis with different amounts of PEG 10, urea, acetic acid, TMOS and VTMS, according to Table 1 . The sol-gel solution was stirred at $0{ }^{\circ} \mathrm{C}$ for $1 \mathrm{~h}$ to obtain a homogeneous solution. This mixture was introduced into the pretreated capillary by a syringe pump and kept at $55^{\circ} \mathrm{C}$ for $12 \mathrm{~h}$ for gelification and ageing in a vacuum oven. Then, the temperature was raised to $120{ }^{\circ} \mathrm{C}$ with a heating ramp of $0.5{ }^{\circ} \mathrm{C} \mathrm{min}^{-1}$ and maintained for $2 \mathrm{~h}$ (this is denoted as monolith 1 ). Some of these columns were flushed with a VDMES/
TEA/MeOH solution and kept at $80{ }^{\circ} \mathrm{C}$ for $24 \mathrm{~h}$. This increases the content of vinyl groups in the monolithic matrix (denoted monolith 2). The derivatization of the hybrid monoliths was carried out via the thiol-ene click reaction between the dodecanethiol and the vinyl groups on the surface of the monoliths. A solution in diethyl ether of dodecanethiol/AIBN (10/0.5 wt.\%) mixture was used to flush the columns that were then incubated at $70{ }^{\circ} \mathrm{C}$ for $12 \mathrm{~h}$. The same process was performed with monoliths 1 and 2 , resulting in monoliths 3 and 4 , respectively. Scheme 1 describes the synthetic procedures for the preparation of these materials and Table 1 presents the amounts of reagents and their effects on the chromatographic and morphological parameters. All the monolithic capillaries were cooled to ambient temperature and washed with $100 \% \mathrm{MeOH}$ between each synthetic step and prior to each analysis. Monolith 1 was also derivatized with a trichlorododecylsilane (TCDDS) solution in toluene for $24 \mathrm{~h}$ at $100{ }^{\circ} \mathrm{C}$ (denoted monolith 5). Three toluene solutions with different contents of TCDDS

Table 1. Effect of synthesis parameters on the formation of vinyl hybrid monoliths

\begin{tabular}{|c|c|c|c|c|c|c|c|c|c|}
\hline Column & $\begin{array}{c}\text { Acetic } \\
\text { acid } / \mathrm{mL}\end{array}$ & $\begin{array}{c}\text { PEG / } \\
\mathrm{mg}\end{array}$ & $\begin{array}{c}\text { Urea / } \\
\text { mg }\end{array}$ & TMOS:VTMS & Optical morphology & $\begin{array}{l}\text { Permeability }(\mathrm{K})^{\mathrm{a}} / \\
\left(\times 10^{-14} \mathrm{~m}^{2}\right)\end{array}$ & $\mathrm{N}^{\mathrm{b}} / \mathrm{m}^{-1}$ & $\mathrm{As}_{10 \%}{ }^{\mathrm{c}}$ & $\mathrm{Rs}^{\mathrm{d}}$ \\
\hline A & 1.8 & 180 & 162 & $3: 1$ & homogeneous and opaque & 0.114 & 11900 & 0.9 & 2.0 \\
\hline B & 2.2 & 180 & 162 & $3: 1$ & slightly detached & 0.117 & 15900 & 1.2 & 3.0 \\
\hline $\mathrm{C}$ & 1.8 & 220 & 162 & $2.5: 1$ & homogeneous and opaque & 0.111 & 1800 & 1.0 & 1.1 \\
\hline $\mathrm{D}$ & 2.2 & 220 & 162 & $3.6: 1$ & homogeneous and opaque & 7.990 & 10000 & 1.3 & 2.2 \\
\hline $\mathrm{E}$ & 1.8 & 180 & 198 & $3.6: 1$ & seriously detached & $--^{\mathrm{e}}$ & - & - & - \\
\hline $\mathrm{F}$ & 2.2 & 180 & 198 & $2.5: 1$ & seriously detached & $-^{\mathrm{e}}$ & - & - & - \\
\hline G & 1.8 & 220 & 198 & $3: 1$ & homogeneous and opaque & $--^{\mathrm{e}}$ & - & - & - \\
\hline $\mathrm{H}$ & 2.0 & 200 & 180 & $3: 1$ & homogeneous and opaque & 0.127 & 16500 & 1.2 & 3.6 \\
\hline $\mathrm{I}^{\mathrm{f}}$ & 2.0 & 200 & 180 & $3: 1$ & $\begin{array}{l}\text { homogeneous and } \\
\text { transparent }\end{array}$ & 7.470 & 1400 & 1.1 & 1.7 \\
\hline $\mathrm{J}^{\mathrm{g}}$ & 2.0 & 200 & 180 & $3: 1$ & $\begin{array}{l}\text { homogeneous and } \\
\text { transparent }\end{array}$ & 3.760 & 4300 & 1.4 & 2.3 \\
\hline $\mathrm{K}^{\mathrm{h}}$ & 2.0 & 200 & 180 & $3: 1$ & $\begin{array}{l}\text { homogeneous and } \\
\text { transparent }\end{array}$ & $--^{\mathrm{e}}$ & - & - & - \\
\hline
\end{tabular}

${ }^{\mathrm{a}} \mathrm{K}=\mathrm{F} \times \eta \times \mathrm{L} /\left(\Delta \mathrm{P} \times \pi \times \mathrm{r}^{2}\right)$, where $\mathrm{F}$ is the mobile phase flow rate, $\eta$ is the mobile phase viscosity, $\Delta \mathrm{P}$ is the pressure drop across the column, $\mathrm{L}$ is the column length, and $\mathrm{r}$ is the inner radius of the column ${ }^{26}$ Backpressure was obtained with $\mathrm{ACN}: \mathrm{H}_{2} \mathrm{O} 90: 10(\mathrm{v} / \mathrm{v})$ as mobile phase at $0.7 \mu \mathrm{L} \mathrm{min}{ }^{-1}$; befficiency (plates $\mathrm{m}^{-1}$ ) where $\mathrm{N}$ can be calculated based on the formula: $\mathrm{N}=5.54\left(\frac{\mathrm{t}_{\mathrm{R}}}{\mathrm{w}_{50 \%}}\right)$, where $\mathrm{t}_{\mathrm{R}}$ is the retention time and $\mathrm{w}_{50 \%}$ is the peak width at half-height; ${ }^{\mathrm{c}} \mathrm{As}_{10 \%}$ : asymmetry for the most retained compound, calculated based on the formula: $\mathrm{A}=\frac{\mathrm{wB}_{10 \%}}{\mathrm{wA}_{10 \%}}$, where $\mathrm{wA}_{10 \%}$ is the peak width of the right half side of the peak and $\mathrm{wB}_{10 \%}$ is the peak width of the left half side of the peak; dresolution factor (Rs) between adjacent peaks 5-6 of alkylbenzene mixtures calculated based on the formula: $2\left(\frac{t_{R_{2}}-t_{R_{1}}}{w_{b 1}+w_{b 2}}\right)$, where $t_{R}$ is the retention time and $w_{b}$ is the peak width; ${ }^{e}$ too dense to pump through the capillary; the monolith was prepared in the same way as monolith $\mathrm{H}$ through the $1^{\text {st }}$ step. Then the monolith was reacted with a 30:70 (v/v) TCDDS/toluene solution; ${ }^{\mathrm{g}}$ the monolith was prepared in the same way as monolith $\mathrm{H}$ through the $1^{\text {st }}$ step. Then the monolith was reacted with a 50:50 (v/v) TCDDS/toluene solution; hthe monolith was prepared in the same way as monolith $\mathrm{H}$ through the $1^{\text {st }}$ step. Then the monolith was reacted with a 70:30 (v/v) TCDDS/toluene solution. PEG: poly(ethylene glycol); TMOS:VTMS: tetramethoxysilane:vinyltrimethoxysilane. PEG: poly(ethylene glycol); TMOS: tetramethoxysilane; VTMS: vinyltrimethoxysilane. 


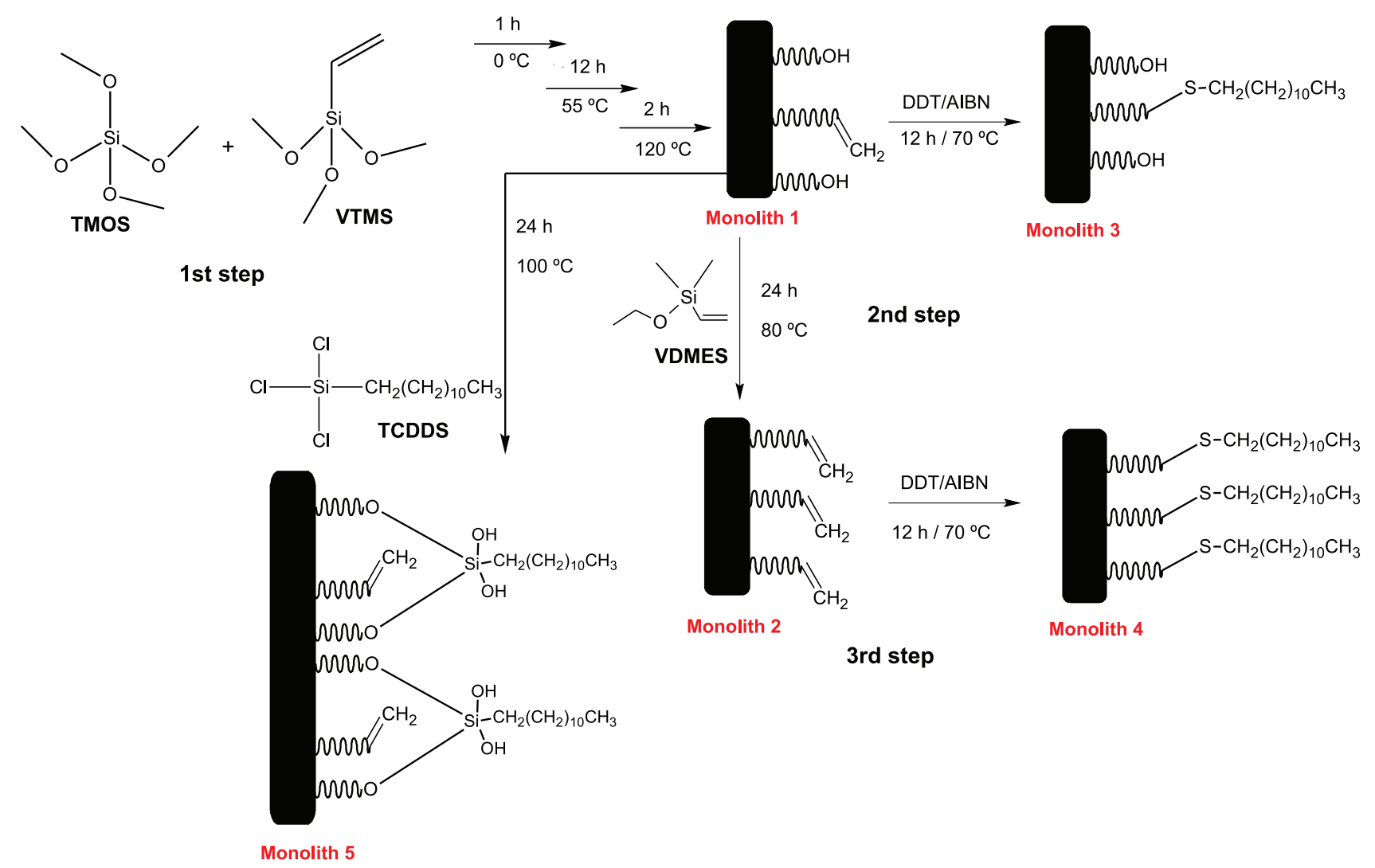

Scheme 1. Synthesis route and functionalization of organic-silica hybrid monoliths based on the thiol-ene click reaction.

were used to functionalize the hybrid silica monolith: $30 \%$ (column I), 50\% (column J) and 70\% (column K).

\section{Physical characterization}

Evaluations of column contents were made by optical microscopy with a Motic BA300 microscope (Diadema, Brazil). The morphological evaluation of the monolithic columns was made by scanning electron microscopy (SEM), using a Jeol JSM-6360 (Tokyo, Japan). The extremities of the capillaries were cut off and cross-sections portions of approximately $5 \mathrm{~mm}$ length were fixed with a double-sided carbon tape onto the sample holder. Then, they were covered with an $\mathrm{Au} / \mathrm{Pd}$ metallization of about $10 \mathrm{~nm}$ thickness. The micrographs were obtained with several magnifications, to provide the best visualization of the morphology of the stationary phase. A Fourier-transform infrared (FTIR) system, CARY 630, Agilent Technologies (Santa Clara, USA), was used to provide the infrared spectra of monolith bulks, without any sample preparation. Evaluation of packing homogeneity in capillary columns was performed with scanning capacitively coupled contactless conductivity detection $\left(\mathrm{sC}^{4} \mathrm{D}\right)$. The $\mathrm{C}^{4} \mathrm{D}$ was a lab made system. A syringe pump was used to push the capillary through the system with a constant speed $\left(\mathrm{cm} \mathrm{s}^{-1}\right) .^{27,28}$

\section{Chromatographic experiments}

The chromatographic characterization was performed using an UltiMate 3000 capillary liquid chromatograph from Thermo Scientific (San Jose, USA). All the columns $(20 \mathrm{~cm} \times 100 \mu \mathrm{m}$ i.d. $)$ presented in Table 1 were evaluated, however, only columns A, B, C, D and $\mathrm{H}$ allowed the chromatographic characterization which requires permeability of the stationary phase. A test mixture containing six alkylbenzenes (benzene, toluene, ethylbenzene, propylbenzene, butylbenzene and pentylbenzene) and another with polycyclic aromatic hydrocarbons (PAH, naphthalene, anthracene, acenaphthene and pyrene) were dissolved in 70:30 (v/v) acetonitrile:water. The detection was performed at 215 and $254 \mathrm{~nm}$ using a UV-Vis detector from Thermo Scientific (San Jose, USA) with a detection cell of $3 \mathrm{~nL}$, the injection volume was $35 \mathrm{~nL}$. The separation was carried out at $25{ }^{\circ} \mathrm{C}$ with a flow rate of $1.2 \mu \mathrm{L} \mathrm{min}{ }^{-1}$ with a $45: 55(\mathrm{v} / \mathrm{v})$ acetonitrile:water mobile phase. The data were processed using Chromeleon 6.8 software. 

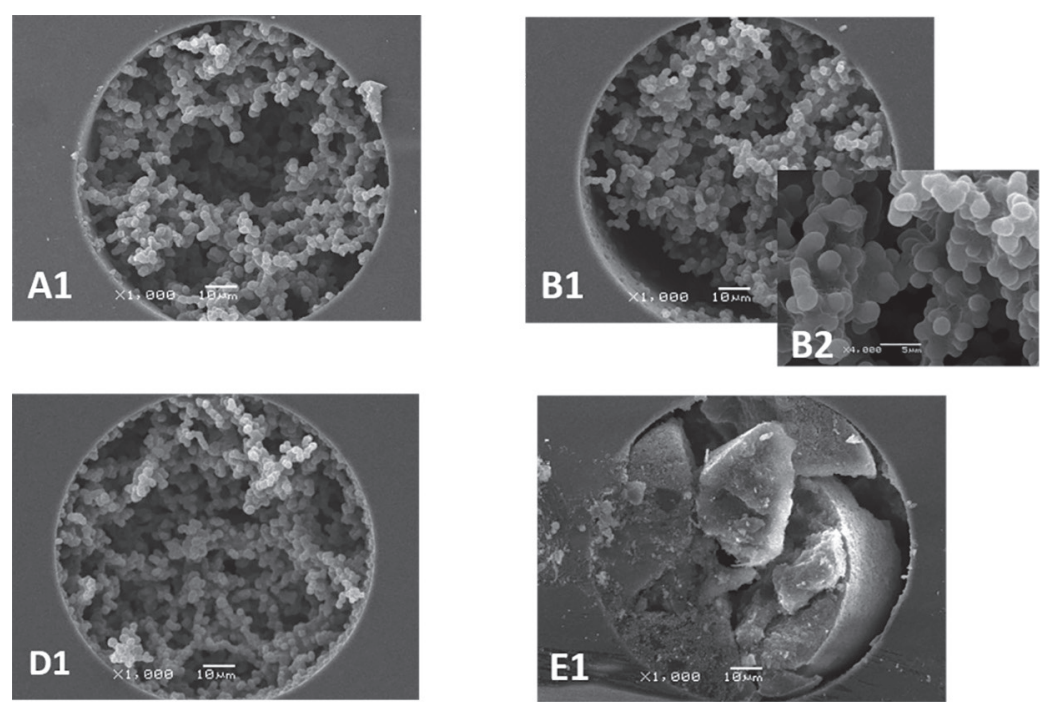
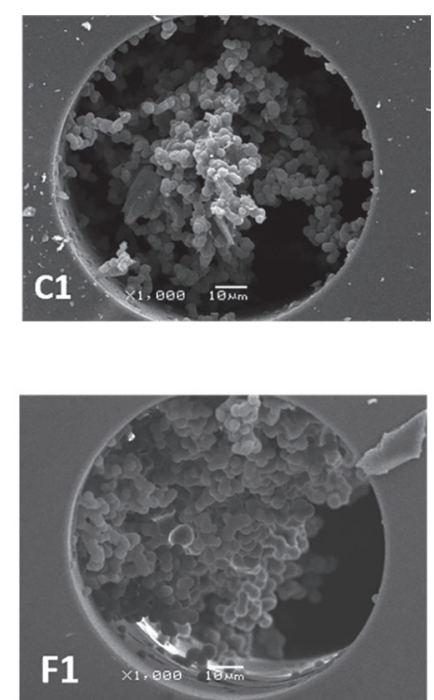
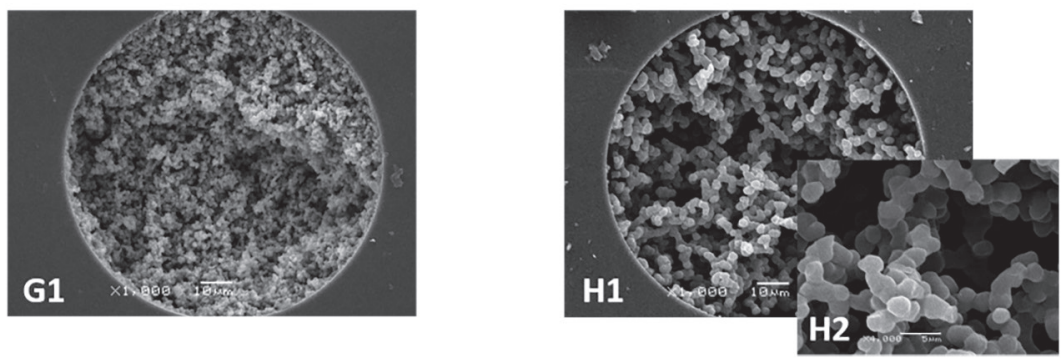

Figure 1. Scanning electron microscopy images of the hybrid columns (A-H) with $1000 \times(1)$ and 4000× (2) magnifications.

\section{Results and Discussion}

\section{Physical characterization of the monolith}

\section{Scanning electron microscopy}

The morphology of the synthesized monolithic materials A-H described in Table 1, can be seen in Figure 1. The SEM images show the effect of the contents of the mixtures on the structure of the monolithic material. Thus, monoliths with higher amounts of urea (E, F and $\mathrm{G})$ presented a solid or very dense monolithic filling, due to thermal decomposition of urea at elevated temperatures. ${ }^{22}$ Despite the good morphology of column B, the micrography displays incomplete adhesion to the capillary tube wall, showing shrinkage of the material. Columns A, D and H present a structure with good adhesion to the inner wall of the capillary, small domains and no shrinkage.

\section{Fourier-transform infrared (FTIR) spectroscopy}

The infrared spectra of the bulks of monoliths 1-4 (Scheme 1), as shown in Figure 2, were measured to evaluate the surface derivatization of the monolithic materials. The absorption bands at 2924, 2855, 1621, 1457 and $1032 \mathrm{~cm}^{-1}$ correspond to thiol alkane chain $-\mathrm{CH}_{2} \cdot{ }^{29-32}$ Comparing spectra 3 and 4 of the monoliths, it is possible to see more intense absorption bands at $778 \mathrm{~cm}^{-1}$ of thiol due the higher content of vinyl groups $\mathrm{s}^{31,33}$ and the alkyl chain, represented by the two peaks in the region of 2924 and $2855 \mathrm{~cm}^{-1}$ that show $\mathrm{C}-\mathrm{H}$ stretching of methyl and methylene groups. ${ }^{30}$ These results are in agreement with the literature..$^{16,34,35}$

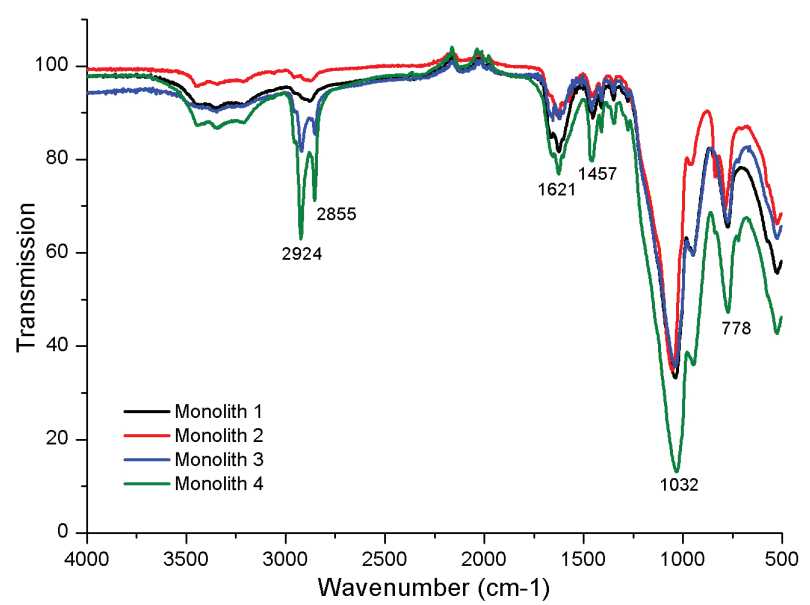

Figure 2. FTIR spectra from the different steps in the synthesis of the monolith matrix of column $\mathrm{H}$.

Scanning capacitively coupled conductivity detection $\left(\mathrm{SC}^{4} \mathrm{D}\right)$

In 2004, Connolly et al..$^{27}$ presented the first practical application of $\mathrm{sC}^{4} \mathrm{D}$, using this technique to accurately 
identify the location of tiny cracks in a silica monolith capillary column. A physical profiling of the monolithic columns is obtained when using this technique along with optical and electron microscopy. Analyzing Figure 3, a flat signal can be seen evidencing either a void column or a constant filling, plus a noise signal. This is feature of a heterogeneous filling, according to Connolly et al. ${ }^{27}$ and Nesterenko et al..$^{36} \mathrm{~A}$ noiseless profile was also observed by Nesterenko et al. ${ }^{36}$ in a monolithic porous layer open tubular (monoPLOT) capillary column. Column B presents

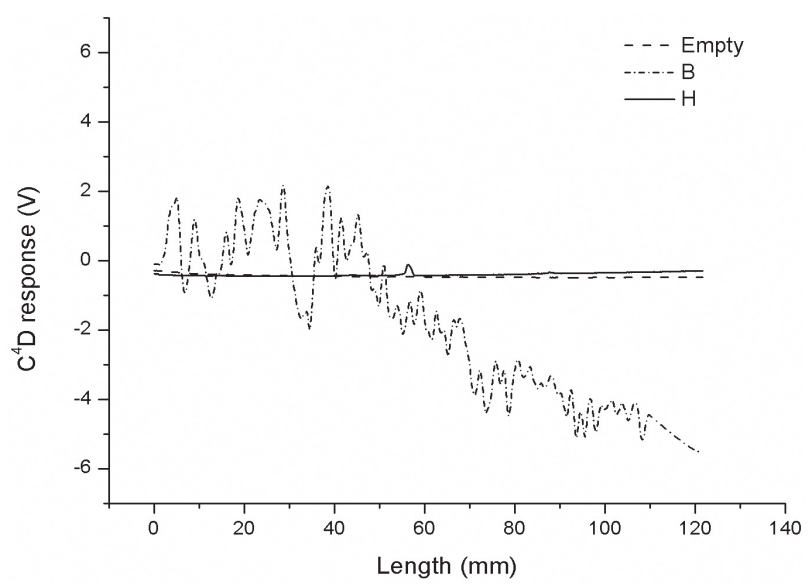

Figure 3. Scanning capacitively coupled contactless conductivity detection $\left(\mathrm{sC}^{4} \mathrm{D}\right)$ profiles of three different columns, an empty one (dashed line), column B (dash-dotted line), and column H (solid line).
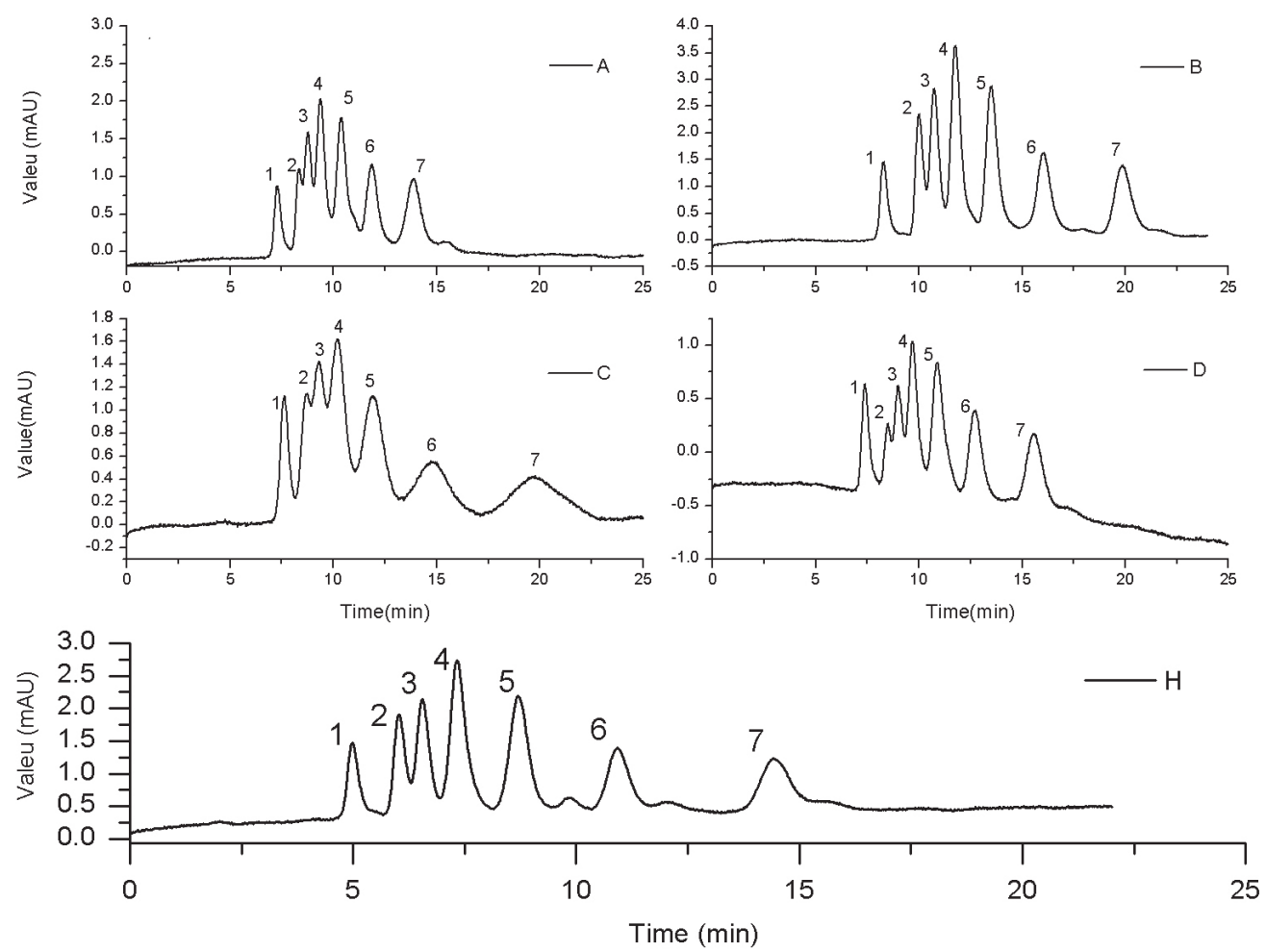

Figure 4. Separation of alkylbenzenes with vinyl-thiol-ene hybrid columns (A, B, C, D and H) using 50:50 (v/v) ACN: $\mathrm{H}_{2} \mathrm{O}$, flow rate $0.7 \mu \mathrm{L}$ min ${ }^{-1}$, detection $215 \mathrm{~nm}, 3 \mathrm{~nL}$ flow cell and $35 \mathrm{~nL}$ injections. Alkylbenzenes: (1) uracil; (2) benzene; (3) toluene; (4) ethylbenzene; (5) propylbenzene; (6) butylbenzene and (7) pentylbenzene.

a good morphology in SEM images but in $\mathrm{SC}^{4} \mathrm{D}$ it shows an unstable profile, higher density from the beginning to the middle of the column and a lower density from the middle to the end, resulting in a poorer column, compared to column H. On the other hand, column H exhibits a constant signal that, when evaluated together with the SEM image, characterizes a well-filled capillary. Other scans of the synthesized columns (A, C, D, E, F and G) can be found in Figure S1 (Supplementary Information (SI) section).

\section{Chromatographic evaluation}

Chromatographic evaluation of the hybrid monolithic capillary columns

The vinyl-thiol-ene hybrid monolithic columns (monolith 4) were used for the separation of alkylbenzenes, shown in Figure 4. Columns E, F and G could not be tested chromatographically due to clogging of the columns. Columns A, C and D do not present good efficiency despite their homogeneous structure. Monolith $\mathrm{C}$ was not totally adhered to the column wall, probably the cause of lower efficiency. The higher permeability of column D (Table 1) can be explained by the low difference of backpressure between the filled and empty column, indicating holes in the structure and lower efficiency. ${ }^{29}$ Column B showed good separation of the compounds, as did column $\mathrm{H}$, and both
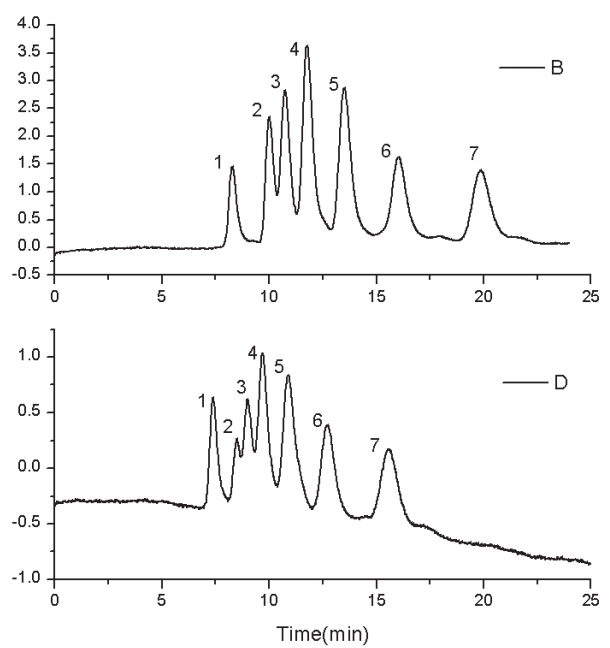
present good efficiencies, asymmetries and resolutions, as can be seen in Table 1, which presents these chromatographic parameters. Based on the SEM images, chromatographic performance and analysis of the $\mathrm{SC}^{4} \mathrm{D}$ profiles, it can be concluded that column $\mathrm{H}$ presented the best results. This is due to a constant internal morphology along the capillary, as evidenced by the measured $\mathrm{sC}^{4} \mathrm{D}$ profile. Figure 5 shows the chromatograms for alkylbenzenes and PAH obtained with column $\mathrm{H}$, leading to a satisfactory separation of these compounds. Capillary monolithic columns B and $\mathrm{H}$ presented efficiencies (plates $\mathrm{m}^{-1}$ ) of 15900 and 16500 , respectively, with asymmetries $\left(\mathrm{As}_{10 \%}\right)$ of 1.2 in both cases. Efficiency values above 20000 plates $\mathrm{m}^{-1}$ for capillary monolithic columns are considered satisfactory for chromatographic separations,${ }^{37}$ although the literature presents values between $90000-110000$ plates $\mathrm{m}^{-1}$ for other types of hybrid monoliths. ${ }^{38-40}$ For asymmetry, values between 0.9 and 1.2 are considered satisfactory according to the United States Pharmacopeia (USP). ${ }^{41}$

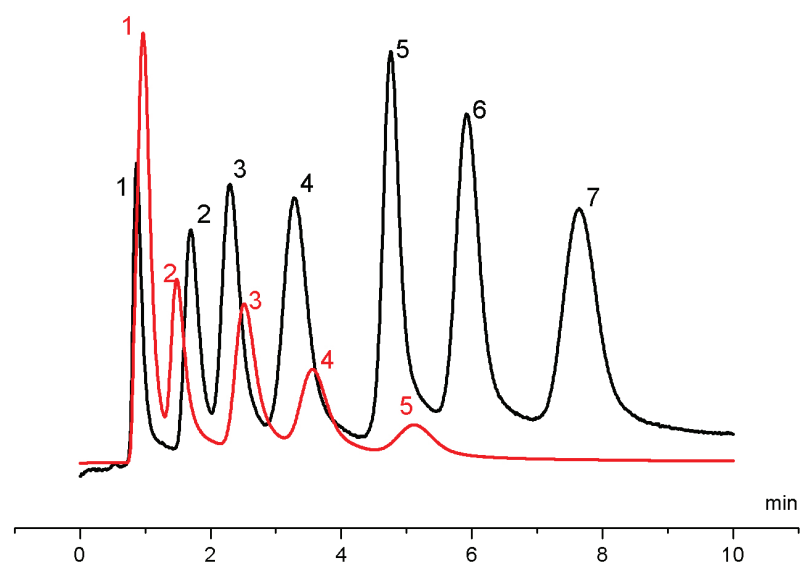

Figure 5. Chromatograms with column H. Separation of alkylbenzenes (black) and PAH (red) using $\mathrm{ACN}: \mathrm{H}_{2} \mathrm{O} 50: 50$ (v/v), flow rate $2.0 \mu \mathrm{L} \mathrm{min}^{-1}$, detection $215 \mathrm{~nm}, 3 \mathrm{~nL}$ flow cell and $35 \mathrm{~nL}$ of injection. Alkylbenzenes (black): (1) uracil; (2) benzene; (3) toluene; (4) ethylbenzene; (5) propylbenzene; (6) butylbenzene and (7) pentylbenzene; PAH (red): (1) uracil; (2) naphthalene; (3) anthracene; (4) acenaphthene and (5) pyrene.

To compare the columns having monoliths 3 and 4, a mixture of alkylbenzenes was used, as seen in Figure 6. Monolith 3 does not present selectivity, which can be explained by the low presence of functional groups on the surface of the material. ${ }^{42}$ The third step of the synthesis increases the content of vinyl groups in the matrix of monolith 4 , allowing the separation of the proposed compounds with good efficiency. ${ }^{22}$

A bonded-phase with $C_{12}$ alkyl group (monolith 5) was prepared from monolith 1 , filling the capillary with a solution of TCDDS in toluene, in different proportions. In this case, monolith 1 was used because of the presence

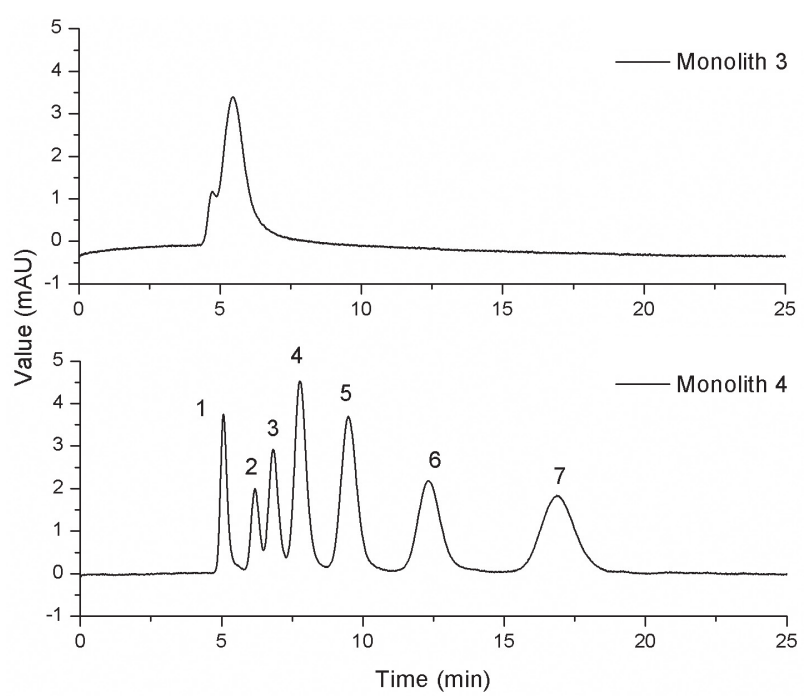

Figure 6. Comparison of the chromatographic profiles of monoliths 3 and 4. Separation of the alkylbenzene mixture using $\mathrm{ACN}: \mathrm{H}_{2} \mathrm{O}$ 45:55 $(\mathrm{v} / \mathrm{v})$, flow rate $1.2 \mu \mathrm{L} \mathrm{min}^{-1}$, detection $215 \mathrm{~nm}, 3 \mathrm{~nL}$ flow cell and $35 \mathrm{~nL}$ injections. Identification of the compounds as in Figure 5.

of surface silanol groups, which are suitable for surface derivatization, while monolith 2 is rich in vinyl groups, incompatible with traditional alkylsilane reactions. The contents of TCDDS in the solutions, 30\% (column I), $50 \%$ (column J) and $70 \%$ (column K), provided columns with different features. Columns I and J did not present clogging, had a homogeneous optical morphology and permeabilities of $7.470 \times 10^{-14}$ and $3.760 \times 10^{-14} \mathrm{~m}^{2}$, respectively, but lower efficiencies (1400 and 4300 plates $\mathrm{m}^{-1}$, respectively), compared to column $\mathrm{H}$ (16500 plates $\left.\mathrm{m}^{-1}\right)$, probably due to the lack of homogeneity of the groups on the surface of monolith 1 . Column K, prepared using the $70 \%$ solution, got clogged and did not allow chromatographic evaluation. This can be explained by the high content of trichlorosilane groups causing a higher cross polymerization, leading to clogging. On the other hand, the hypervinylization reaction with VDMES on monolith 2 ensured that all the sites were replaced by vinyl groups, which were suitable for the thiolene reaction, resulting in a stable phase with good efficiency.

To compare the separation profiles of monoliths 4 and 5 (dodecanethiol and dodecanesilane), the chromatographic evaluations of columns $\mathrm{H}$, I and J were performed

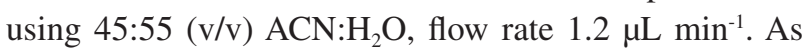
shown in Figure 7, the efficiency of columns I and J was still lower than that of the thiol-ene hybrid monolithic column $(\mathrm{H})$.

\section{Chemical stability}

The column stability of the hybrid monolith synthesized with dodecanethiol was performed for 8000 column volumes (185 injections, one every $35 \mathrm{~min}$ ) using the same chromatographic conditions as presented in Figure 5. As 

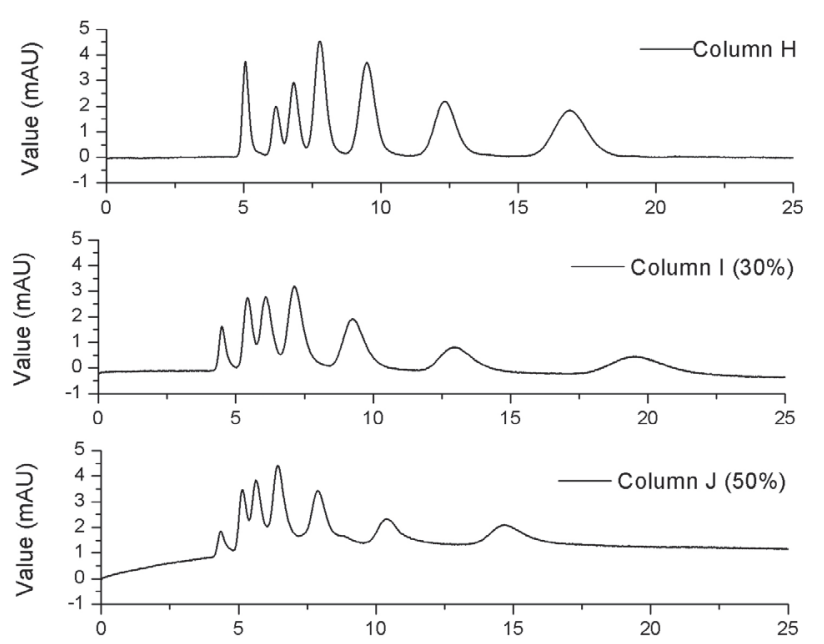

Figure 7. Effect of the volume ratio of dodecanesilane in toluene on the efficiency, comparing dodecanethiol columns and a dodecylfunctionalized hybrid silica column. Separation of the alkylbenzene mixture using $\mathrm{ACN}: \mathrm{H}_{2} \mathrm{O} 45: 55(\mathrm{v} / \mathrm{v})$, flow rate $1.2 \mu \mathrm{L} \mathrm{min}{ }^{-1}$, detection $215 \mathrm{~nm}, 3 \mathrm{~nL}$ flow cell and $35 \mathrm{~nL}$ of injection.

seen in Figure 8, the asymmetry and retention factor were unchanged throughout the chromatographic analyses of uracil and propylbenzene up to the end of the test. The stability presented for this dodecanethiol hybrid monolithic column are probably due to the fact that the cleavage of the $\mathrm{Si}-\mathrm{S}$ bond on the surface silica is difficult to occur. This kind of test, despite being important, is not commonly reported in monolithic column evaluations.

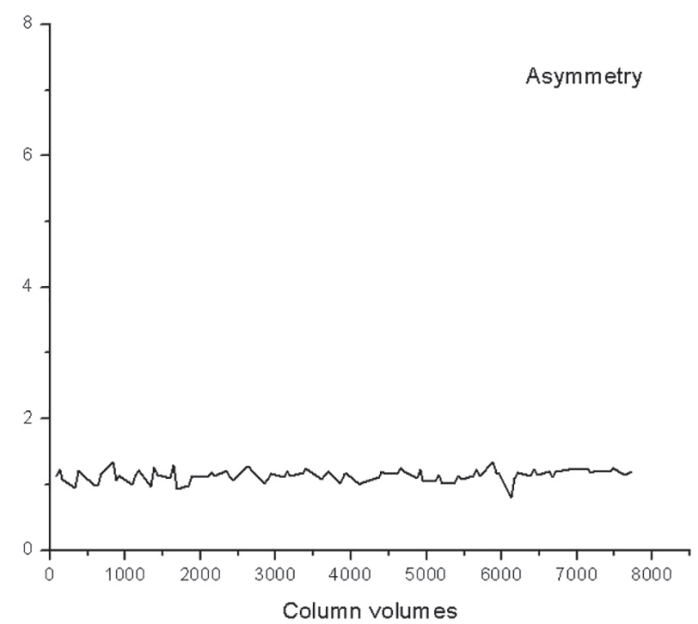

\section{Conclusions}

A vinyl-functionalized polymer-silica hybrid monolith was successfully prepared through the sol-gel process followed by derivatization via thiol-ene click chemistry. The optimized dodecanethiol monolithic column showed a homogeneous morphology without shrinkage, reasonable efficiency (around 16000 plates $^{-1}$ ), and chemical stability to at least 8000 column volumes. Compared to a dodecanesilane bonded phase, the vinyl thiol-ene hybrid columns exhibited higher efficiency and satisfactory separation performance.

\section{Supplementary Information}

Supplementary data are available free of charge at http://jbcs.sbq.org.br as PDF file.

\section{Acknowledgments}

The authors acknowledge financial support from the Fundação de Amparo à Pesquisa do Estado de São Paulo (FAPESP), grant 2014/50867-3 and the Conselho Nacional de Desenvolvimento Científico e Tecnológico (CNPq), grants 311671/2015-2 and 465389/2014-7. This work was supported by the National Institute of Bioanalytical Chemistry (INCT Bioanalítica). The authors also thank Professor Carol H. Collins for language assistance.

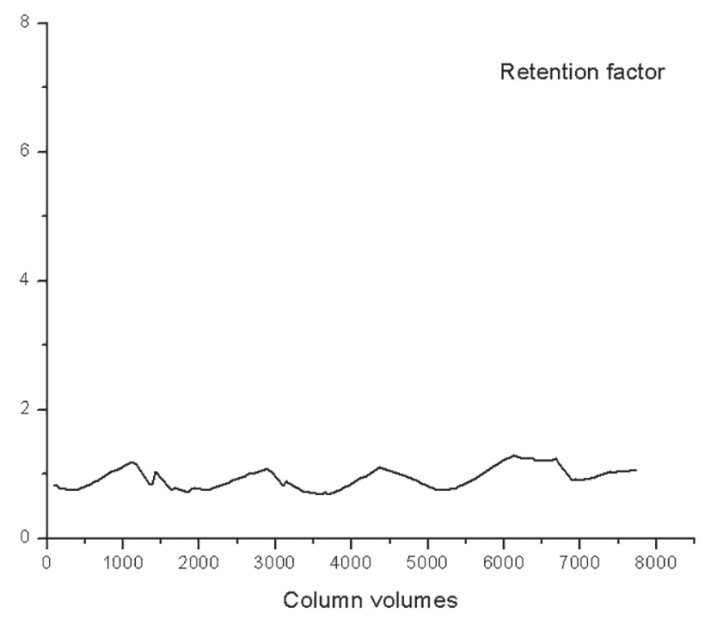

Figure 8. Chemical stability of dodecanethiol stationary phase (column $\mathrm{H}$ ) for 8000 column volumes. The chromatographic conditions were $\mathrm{ACN}: \mathrm{H}_{2} \mathrm{O}$ 45:55 (v/v); $1.2 \mu \mathrm{L} \mathrm{min}-1$, detection $215 \mathrm{~nm}, 3 \mathrm{~nL}$ flow cell and $35 \mathrm{~nL}$ injections. The compounds used for the evaluations were uracil and propylbenzene in both cases.

\section{References}

1. Silva, R. G. C.; Collins, C. H.; Bottoli, C. B. G.; Quim. Nova 2011, 34, 841 .

2. Racha, E.-D.; Gay, P.; Dugas, V.; Demesmay, C.; J. Sep. Sci. 2016, 39, 842 .
3. Zajickova, Z.; J. Sep. Sci. 2017, 40, 25.

4. Núñez, O.; Nakanishi, K.; Tanaka, N.; J. Chromatogr. A 2008, $1191,231$.

5. Jandera, P.; Urban, J.; Škeříková, V.; Langmaier, P.; Kubíčková, R.; Planeta, J.; J. Chromatogr. A 2010, 1217, 22.

6. Nazario, C. E. D.; Silva, M. R.; Franco, M. S.; Lanças, F. M.; 
J. Chromatogr. A 2015, 1421, 18.

7. Wu, R.; Hu, L.; Wang, F.; Ye, M.; Zou, H.; J. Chromatogr. A 2008, 1184, 369.

8. Hong, T.; Yang, X.; Xu, Y.; Ji, Y.; Anal. Chim. Acta 2016, 931, 1.

9. Tanaka, N.; Unger, K. K. In Monolithic Silicas in Separation Science-Concepts, Syntheses, Characterization, Modeling and Applications; Unger, K. K.; Tanaka, N.; Machtejevas, E., eds.; Wiley-VCH: Weinhein, 2011, p. 2-4.

10. Liu, S.; Peng, J.; Liu, Z.; Liu, Z.; Zhang, H.; Wu, R.; Sci. Rep. 2016, 6, 34718.

11. Guiochon, G.; J. Chromatogr. A 2007, 1168, 101.

12. Ou, J.; Liu, Z.; Wang, H.; Lin, H.; Dong, J.; Zou, H.; Electrophoresis 2015, 36, 62.

13. Hayes, J. D.; Malik, A.; Anal. Chem. 2000, 72, 4090.

14. Wu, M.; Wu, R.; Zhang, Z.; Zou, H.; Electrophoresis 2011, 32, 105.

15. Zhang, Z.; Hao, Y. H.; Ding, J.; Xu, S. N.; Yuan, B. F.; Feng, Y. Q.; J. Chromatogr. A 2015, 1416, 64.

16. Liu, Z.; Liu, J.; Liu, Z.; Wang, H.; Ou, J.; Ye, M.; Zou, H.; J. Chromatogr. A 2017, 1498, 29.

17. Zhang, Z.; Lin, H.; Ou, J.; Qin, H.; Wu, R.; Dong, J.; Zou, H.; J. Chromatogr. A 2012, 1228, 263.

18. Ou, J.; Lin, H.; Zhang, Z.; Huang, G.; Dong, J.; Zou, H.; Electrophoresis 2013, 34, 126.

19. Jonnada, M.; Rathnasekara, R.; El Rassi, Z.; Electrophoresis $\mathbf{2 0 1 5}, 36,76$.

20. Liu, Z.; Ou, J.; Zou, H.; TrAC, Trends Anal. Chem. 2016, 82, 89.

21. Kolb, H. C.; Finn, M. G.; Sharpless, K. B.; Angew. Chem., Int. Ed. 2001, 40, 2004.

22. Wang, K.; Chen, Y.; Yang, H.; Li, Y.; Nie, L.; Yao, S.; Talanta 2012, 91, 52 .

23. Lv, X.; Tan, W.; Chen, Y.; Chen, Y.; Ma, M.; Chen, B.; Yao, S.; J. Chromatogr. A 2016, 1454, 49.

24. Wang, H.; Hu, W.; Zheng, Q.; Bian, W.; Lin, Z.; J. Sep. Sci. 2017, 40, 2344.

25. Zeng, J.; Liu, S.; Wang, M.; Yao, S.; Chen, Y.; Electrophoresis 2017, 38, 1325.

26. Bristow, P. A.; Knox, J. H.; Chromatographia 1977, 10, 279.
27. Connolly, D.; Floris, P.; Paull, B.; Nesterenko, P. N.; TrAC, Trends Anal. Chem. 2010, 29, 870.

28. Brito-Neto, J. G. A.; da Silva, J. A. F.; Blanes, L.; do Lago, C. L.; Electroanalysis 2005, 17, 1198.

29. Ma, S.; Zhang, H.; Li, Y.; Li, Y.; Zhang, N.; Ou, J.; Ye, M.; Wei, Y.; J. Chromatogr. A 2018, 1538, 8.

30. Zhang, N.; Zhang, L.; Qiao, X.; Wang, Y.; Yan, H.; Bai, L.; RSC Adv. 2015, 5, 91436.

31. Shen, S.; Ye, F.; Zhang, C.; Xiong, Y.; Su, L.; Zhao, S.; Analyst 2014, 140, 265.

32. Liu, Z.; Ou, J.; Lin, H.; Wang, H.; Dong, J.; Zou, H.; J. Chromatogr. A 2014, 1342, 70.

33. Lin-Vien, D.; Colthup, N. B.; Fateley, W. G.; Grasselli, J. G.; The Handbook of Infrared and Raman Characteristic Frequencies of Organic Molecules, vol. 4; Elsevier: San Diego, 1991, p. 225-250.

34. Alimohammadi, F.; Wang, C.; Durham, O. Z.; Norton, H. R.; Bowman, C. N.; Shipp, D. A.; Polymer (Guildf.) 2016, 105, 180.

35. Liu, Z.; Ou, J.; Lin, H.; Wang, H.; Liu, Z.; Dong, J.; Zou, H.; Anal. Chem. 2014, 86, 12334.

36. Nesterenko, E. P.; Burke, M.; de Bosset, C.; Pessutto, P.; Malafosse, C.; Collins, D. A.; RSC Adv. 2015, 5, 7890.

37. da Silva, C. G. A.; Collins, C. H.; Bottoli, C. B. G.; Microchem. J. 2014, 116, 249.

38. Codesido, S.; Rudaz, S.; Veuthey, J.-L.; Guillarme, D.; Desmet, G.; Fekete, S.; J. Chromatogr. A 2019, 1603, 208.

39. Chen, M. L.; Zhang, J.; Zhang, Z.; Yuan, B. F.; Yu, Q. W.; Feng, Y. Q.; J. Chromatogr. A 2013, 1284, 118.

40. Lin, H.; Ou, J.; Zhang, Z.; Dong, J.; Wu, M.; Zou, H.; Anal. Chem. 2012, 84, 2721.

41. Snyder, L. R.; Kirkland, J. J.; Dolan, J. W.; Introduction to Modern Liquid Chromatography, $3^{\text {rd }}$ ed.; Wiley: Hoboken, USA, 2010.

42. Kirkland, J. J.; Glajch, J. L.; Farlee, R. D.; Anal. Chem. 1989, $61,2$.

Submitted: February 8, 2019

Published online: July 26, 2019 